\title{
Toward the identification of a phytocannabinoid-like compound in the flowers of a South African medicinal plant (Leonotis leonurus)
}

\author{
E. Hunter ${ }^{1}$, M. Stander ${ }^{2}$, J. Kossmann ${ }^{1}$, S. Chakraborty ${ }^{3}$, S. Prince ${ }^{3}$, S. Peters ${ }^{1 \dagger}$ and Bianke Loedolff ${ }^{*+}$ (1)
}

\begin{abstract}
Objective: Current global trends on natural therapeutics suggest an increasing market interest toward the use and discovery of new plant-derived therapeutic compounds, often referred to as traditional medicine (TM). The Cannabis industry is currently one such focal area receiving attention, owing to the occurrence of phytocannabinoids ( $\mathrm{pCBs}$ ) which have shown promise in health-promotion and disease prevention. However, the occurrence of $\mathrm{pCBs}$ in other plant species are often overlooked and rarely studied. Leonotis leonurus (L.) R. Br. is endemic to South Africa with a rich history of use in TM practices amongst indigenous people and, has been recorded to induce mild psychoactive effects akin to Cannabis. While the leaves have been well-reported to contain therapeutic phytochemicals, little information exists on the flowers. Consequently, as part of a larger research venture, we targeted the flowers of $L$. leonurus for the identification of potential pCB or pCB-like compounds.

Results: Flower extracts were separated and analyzed using high performance thin layer chromatography (HPTLC). A single PCB candidate was isolated from HPTLC plates and, using liquid chromatography coupled to tandem mass spectrometry (LC-MS/MS), we could successfully group this compound as a fatty amide and tentatively identified as 7,10,13,16-Docosatetraenoylethanolamine (adrenoyl-EA), a known bioactive compound.
\end{abstract}

Keywords: Adrenoyl-EA, Traditional medicine, Phytochemistry, Flowers, Cannabis, Phytocannabinoids, Leonotis leonurus

\section{Introduction}

Increasing interest from developed economies in the use of TMs has created the second largest global therapeutics market $[1,2]$. The medicinal Cannabis industry is currently one such focal area, largely because of the occurrence of phytocannabinoids (pCBs). As part of a unique class of phytochemicals that interact with the

\footnotetext{
*Correspondence: bianke@sun.ac.za

† $S$ Peters and B Loedolff co-senior authors

${ }^{1}$ Department of Genetics, Institute of Plant Biotechnology, Faculty of AgriSciences, Stellenbosch University, Stellenbosch, South Africa Full list of author information is available at the end of the article
}

human endocannabinoid system (ECS), the use of pCBs as therapeutics holds promise in the treatment of numerous chronic diseases [3-8]. However, many countries still abide by strict regulatory laws pertaining to the commercial growth of Cannabis and, consequently research into pharmacologically relevant products has until recently, been relatively protracted. Since the discovery of pCBs, similar compounds (pCB-like) have been reported in several plant species, beyond Cannabis, that are commonly used in TM practices [9]. The growing interest in the use of TMs enabled an opportunity for the discovery and evaluation of new compounds from medicinal and 
non-medicinal plants for the development of natural therapeutics.

The use of the 'wild cannabis' plant, $L$. leonurus (L.) $\mathrm{R}$. Br., endemic to South Africa, is commonly reported in TM to treat numerous ailments including eczema, headaches, hypertension, and chest infections [10, 11]. The leaves (when smoked) have been described to elicit similar effects to Cannabis, including mild psychoactive symptoms, as well as the capacity to alleviate anxiety and induce calming effects $[10,12]$. Despite the amount of research available on the leaves, little to no information exists on the medicinal properties of the flowers of this plant. Furthermore, the occurrence of $\mathrm{pCBs}$ or pCB-like compounds has never been reported. In this research note, we report on the tentative identification of a pCB-like compound (like adrenoyl-EA) in the flowers of the white flower variety Leonotis leonurus var. albiflora Benth.

\section{Main Text}

\section{Materials and methods} Plant material

L. leonurus var. albiflora Benth. seeds (white flower variety) were obtained from a commercial seed supplier (Seeds for Africa, South Africa) and grown on a residential property at the Bottom Road Sanctuary, Zeekoevlei, Western Cape Province, South Africa (GPS coordinates: -34.057951, 18.499391). Flower samples were harvested at mature stage (Fig. 1, photo courtesy of Dr B Loedolff) and immediately stored at $-20^{\circ} \mathrm{C}$.

\section{Whole flower metabolite extraction}

Flowers were lyophilized (20 h; 100 mTorr, $\left.-60{ }^{\circ} \mathrm{C}\right)$ and ground to a fine powder using a pestle and mortar. Metabolites were extracted from flower material $(50 \mathrm{mg}$ ) as previously described [13, 14], evaporated, and the resin reconstituted in $200 \mu \mathrm{L} d \mathrm{ddH}_{2} \mathrm{O}$, calibrating the extracts to $0.50 \mathrm{mg} / \mu \mathrm{L}$.

\section{Phytocannabinoid screening and isolation using HPTLC}

Phytocannabinoid screening was performed on $10 \times 20 \mathrm{~cm}$ glass-back plates pre-coated with $0.25 \mathrm{~mm}$ silicagel 60 (REF 811213, Macherey-Nagel, Germany). Flower derived-extracts $(0.50 \mathrm{mg} / \mu \mathrm{L})$ were applied to the plates in $2 \mu \mathrm{L}$ increments and allowed to dry completely before placement into a glass chromatography chamber (Camag, Switzerland), pre-conditioned with the mobile phase, chloroform:methanol (9:1; $30 \mathrm{~min})$. Subsequently, the chromatogram was developed in the dark using fast blue $B$ reagent $(0.1 \% \mathrm{w} / \mathrm{v}$; dissolved in $1 \mathrm{mM} \mathrm{NaOH})$. Based on $R_{f}$ ranges (comparative to the upper $R_{f}$ values representing the less polar range of $\mathrm{pCBs}$ from Cannabis, under the same chromatographic conditions [15]) and

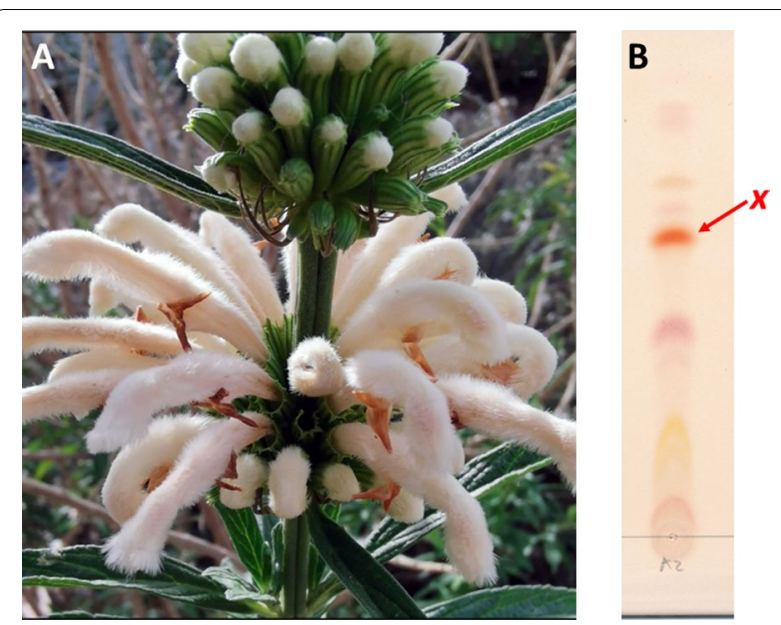

Fig. 1 HPTLC phytochemical profile of Leonotis leonurus var. albiflora Benth. whole flower extract. a L. leonurus var. albiflora Benth. white flower phenotypic appearance (Photo courtesy of Dr B Loedolff) and b its corresponding acetonitrile (75\%) extract, HPTLC phytochemical profile. Whole flower metabolite extractions were prepared using various extraction solvents and, the acetonitrile (75\%) extracts were selected for downstream analyses. The phytochemical profile was developed fully (mobile phase; chloroform:methanol 9:1, stationary phase; silica $60 \AA$ ) before reagent visualization ( $0.1 \%$ Fast blue B salt dissolved in $1 \mathrm{mM} \mathrm{NaOH}$ ) was applied to reveal potential pCB candidates, based solely on an red-orange colour development. Compound $x$ (Rf value: 0.55 ) represents a colorimetric-specific pCB-like candidate compound which was selected for further LC-MS/ MS analyses

change in colour [16]), a single, red-orange compound of interest was scraped from the preparative HPTLC plate and resuspended in $50 \%(\mathrm{v} / \mathrm{v})$ methanol, prior to tandem mass spectrometry (LC-MS/MS) analyses.

\section{Tandem mass spectrometry (LC-MS/MS) analyses}

LC-MS/MS analyses were performed, as previously described [14], with a Waters Synapt G2 quadrupole time-of-flight mass spectrometer (Waters Corporation, Milford, MA, USA) equipped with a Waters Acquity UPLC. Samples were separated on a Waters UPLC BEH C18 column $(2.1 \times 100 \mathrm{~mm} ; 1.7 \mu \mathrm{m})$ at a flow rate of $0.25 \mathrm{ml} / \mathrm{min}$ at $55{ }^{\circ} \mathrm{C}$. Solvent A consisted of $0.1 \%(\mathrm{v} / \mathrm{v})$ formic acid in water and solvent B was $0.1 \%(v / v)$ formic acid in acetonitrile. The mobile phase gradient was initiated at $100 \%$ solvent A for $1 \mathrm{~min}$ and linearly reduced to $28 \%$ solvent A over $22 \mathrm{~min}$. Subsequently, the mobile phase was changed to $40 \%$ solvent B over 8 min followed by a $1 \mathrm{~min}$ wash step in $100 \%$ solvent B before the column was re-equilibrated to the initial conditions for $4 \mathrm{~min}$. Electrospray ionization was applied, and samples were analysed in a negative mode run and a positive mode run. Data was acquired in $\mathrm{MS}^{\mathrm{E}}$ mode, which consists of a high collision energy scan range of $m / z \quad 125-1500$ and 
a low collision energy scan from $m / z 40-1500$. The photo diode array detector was set to scan from $220-600 \mathrm{~nm}$. The capillary voltage was set at $3.5 \mathrm{kV}$ and the collision energy either $6 \mathrm{~V}$ (low collision energy scan from) or 30-60 V (high collision energy scan), the cone voltage was $15 \mathrm{~V}$, the source temperature $120^{\circ} \mathrm{C}$ and the desolvation temperature was $275{ }^{\circ} \mathrm{C}$. The desolvation and cone gas (nitrogen) flows were 650 and $50 \mathrm{~L} / \mathrm{h}$, respectively. Sodium formate was used for calibration and leucine encephalin was infused in the background as lock mass for accurate mass determinations, where authentic reference compounds were available. Metabolites were monitored using their deprotonated quasi-molecular ions.

Compounds were tentatively identified using the Metabolomics workbench [17]. The database was searched, using the $\mathrm{m} / \mathrm{z}$ mass obtained from total ion chromatograms, with parameters set to the negative $[\mathrm{M}-\mathrm{H}]^{-}$and positive ion $[\mathrm{M}+\mathrm{H}]^{+}$mode, respectively, and a mass tolerance of $\pm 0.5 \mathrm{~m} / \mathrm{z}$. Tentative identification was based on the experimental mass of the specific peaks compared to literature and was carried out in conjunction with independent metabolite repositories, Metabolomics Workbench, PubChem, and METLIN Metabolite and Chemical Entity Database.

\section{Results and discussion}

L. leonurus (L.) R. Br. is a drought resistant medicinal shrub endemic to South Africa with a bi-annual flowering season (high-yielding medicinal crop). Anecdotally it is known for eliciting mild psychoactive effects akin to the smoking of Cannabis and, has a long-standing history in traditional healing practices in South Africa. Some studies have alluded to its medicinal activities however, these have largely focused on the leaves and only a few reports have dealt with the flowers $[10,11]$. Furthermore, there are no reports that describe the occurrence of medicinal pCBs from the leaves or the flowers. Since pCBs have been proposed as effective TMs for the prevention and/ or treatment of chronic diseases [18-20], identification of pCBs (or pCB-like compounds) in plants other than Cannabis spp. could present an attractive value proposition to complement the emergent Cannabis industry.

Based on its mild Cannabis-like effect when smoked, we conducted analyses into the flower-derived phytochemicals and the potential presence of $\mathrm{pCB}$-like compounds in L. leonurus var. albiflora Benth. (Fig. 1a). Since extensive phytochemical profiling of the leaves have never yielded any pCB-like compounds $[10,11]$, we suspected that such compounds may be present in flowers (akin to Cannabis). Using HPTLC, coupled to fast blue $\mathrm{B}$ salt as a selective colorimetric detection method for pCB compounds [14], we extracted flower metabolites with gradient concentrations (50, 75 and 100\%) of either methanol or acetonitrile (Additional file 1: Figure $\mathrm{S} 1$ ). The fast blue method detects major neutral cannabinoids such as tetrahydrocannabinol (THC), cannabidiol (CBD), and their cannabinoid acid derivatives THCA and CBDA, among other cannabinoids with high sensitivity and selectivity $[15,16]$.

A single, potential pCB-like compound (distinct redorange colour, $R_{f} 0.55$; Fig. $1 b$ ) was isolated, and its identity tentatively determined using LC-MS/MS in both positive and negative ionization modes (Fig. 2a, b). Mass spectra from whole flower extracts and the isolated HPTLC compound were compared (Fig. 2c, d) resulting in equivalent retention times and peak masses in both negative (RT: $30.78 \mathrm{~min} ;[\mathrm{M}-\mathrm{H}]^{-}=374.26$ ) and positive (RT: $30.77 \mathrm{~min} ;[\mathrm{M}+\mathrm{H}]^{+}=376.26$ ) ionization mode. Further investigation using the international metabolite repositories, Metabolomics Workbench, PubChem, and METLIN Metabolite and Chemical Entity Database, consistently grouped this compound as a fatty amide with tentative identification as 7,10,13,16-Docosatetraenoylethanolamine $\left([\mathrm{M}-\mathrm{H}]^{-}=374.31 ;[\mathrm{M}+\mathrm{H}]^{+}=376.32\right.$; neutral $\mathrm{m} / \mathrm{z}=375.31$ ), also known as adrenoyl-ethanolamide (EA). Adrenoyl-EA is a bioactive endocannabinoid previously thought to be unique to mammals [21, 22]. However, it has recently (and for the first time) been confirmed to occur in methanol extracts of the Mashua plant (Tropaeolum tuberosum), extensively used in Andean folk medicine [23]. Our findings tentatively identify the occurrence of a pCB-like compound (predicted to be like adrenoyl-EA) in acetonitrile extracts from the flowers of L. leonurus var. albiflora Benth.

Adrenoyl-EA is structurally similar to the major endocannabinoid anandamide and functions as an agonist of the $\mathrm{CB}_{1}$ and $T R P V_{1}$ receptor proteins, two major receptors of the human ECS [21, 24]. Agonists of these receptors are ideal candidates in a range of therapeutic targets, specifically exhibiting anti-inflammatory, neuroprotective, and anticancer activities, among others [23, 25, 26]. Within the growing market of TMs, we consider it beneficial to identify sustainable, climate resilient plant resources (high yielding medicinal crops) that accumulate $\mathrm{pCBs}$ or PCB-like compounds with the potential for therapeutic purposes.

\section{A South African perspective on the development of $p C B$ products}

It is estimated that the domestic South Africa Cannabis market will reach USD $\$ 1.8$ billion by 2023 however, this projection is based on export value only, excluding Cannabis-derived $\mathrm{pCB}$ products. The value proposition lies within the latter, given the therapeutic potential of $\mathrm{pCBs}$ in chronic disease treatment [23-26]. South African agriculture is typified by both large scale mechanized, and 

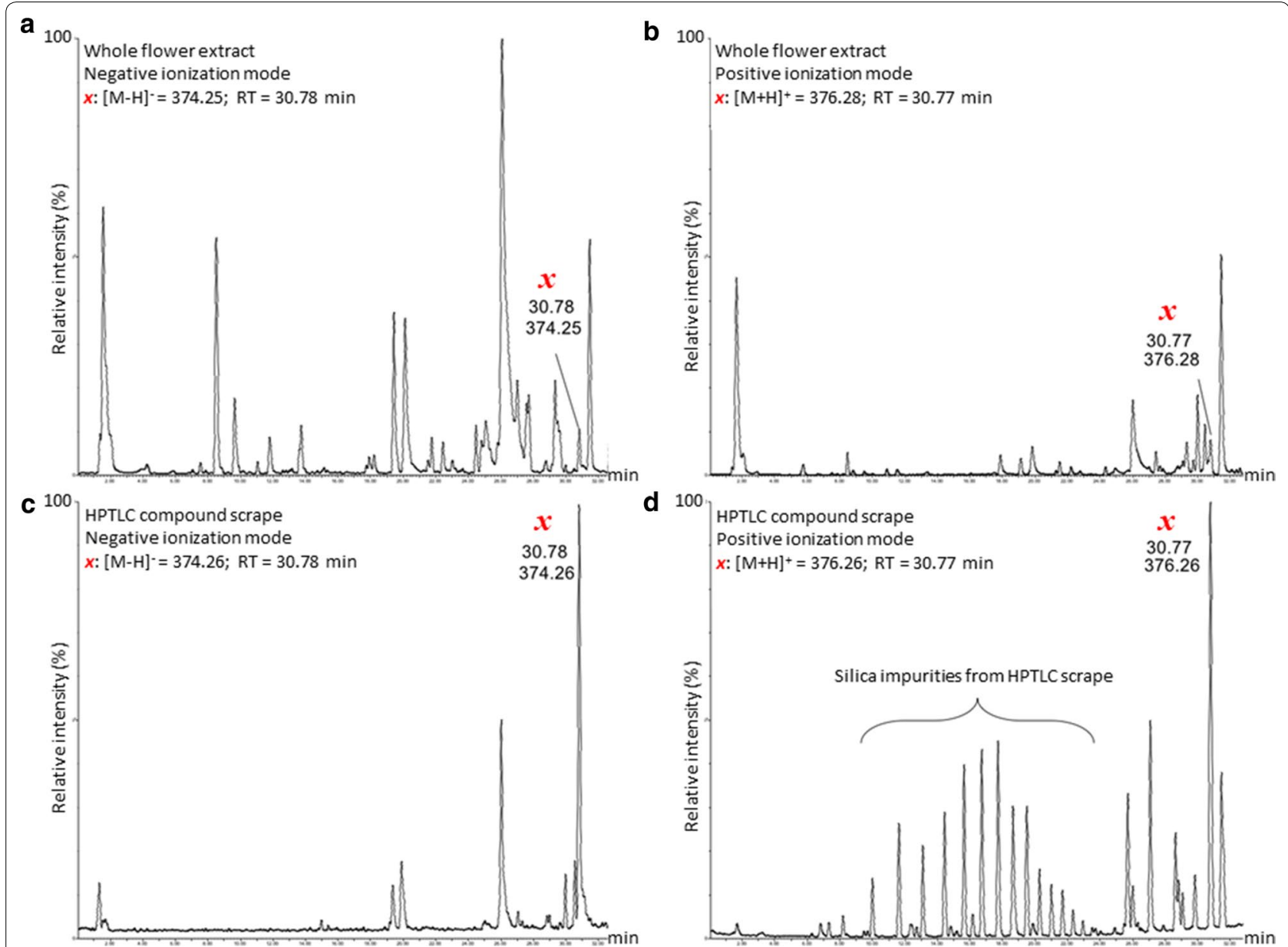

Fig. 2 LC-MS/MS spectra of Leonotis leonurus var. albiflora Benth. whole flower extract, targeting the cannabinoid occurrence in flowers. LC-MS/ MS spectra of white L. leonurus var. albiflora Benth. whole flower extract in negative (a) and positive (b) ionization modes. Spectra of the preparative HPTLC product, compound $x$, in negative (c) and positive (d) ionization modes. In accordance with literature, matching retention times and adduct masses for compound $\boldsymbol{x}$, representing 7,10,13,16-Docosatetraenoylethanolamine, are shown in both ionization modes $\left([\mathrm{M}-\mathrm{H}]^{-}=374.26, \mathrm{RT}\right.$ : $30.78 \mathrm{~min} ;\left([\mathrm{M}+\mathrm{H}]^{+}=376.26, \mathrm{RT}: 30.77 \mathrm{~min}\right)$, where chromatogram axis represent relative mass abundance (\%) and retention time (RT, minutes), respectively

smallholder practices and Cannabis cultivation is considered viable. Although the agricultural experience and arable land in South Africa is adequate for the growth and export of Cannabis, the irrigation infrastructure and required daylight might not be sufficient to sustain the production of high quality Cannabis-derived products. One of the major predicted hurdles in establishing a sustainable Cannabis industry is the water-intensive measures required for an efficient $\mathrm{pCB}$ yield from Cannabis. If one could exploit a water-efficient medicinal crop capable of producing $\mathrm{pCB}$-like compounds, this would serve as an ideal industry alternative into a realm of "smartpharming" practices.

As part of a pCB-driven strategy for the development of high value TMs, we suggest that the discovery of $\mathrm{pCBs}$ in endemic South African plants could be highly complementary to the Cannabis industry, given that these plants are adapted to the climatic and water-scarce conditions. To our knowledge, we provide the first evidence on the presence of the pCB-like compound, adrenoyl-EA, in the flowers of L. leonurus var. albiflora Benth. Globally, the production of $\mathrm{pCBs}$ from these alternative resources could benefit the future TM market, particularly in countries where agriculture is typified by water scarcity.

\section{Limitations}

This research note serves to highlight the potential existence of $\mathrm{pCBs}$ or $\mathrm{pCB}$-like compounds within the whole flower extract of L. leonurus var. albiflora Benth. HPTLC screening indicated the potential existence of several 
pCBs, based on the reported selectivity and color index when developed with the fast blue B reagent. From these, we selected one (isolated by scraping the selected area from the HPTLC plate) for downstream LC-MS/MS analyses. The isolated compound was tentatively identified as pCB-like, with adrenoyl-EA predicted as the main candidate on several databases. A major limitation for this study is the absence of an authentic LC-MS/MS reference compound for adrenoyl-EA to (i) calibrate the instrument and accommodate for potential mass shifts/ corrections and (ii) compare fragmentation and isotope patterning on our instrument. Results discussed here are tentative based on experimental mass and database searches and, further investigations will be required to unequivocally provide evidence for the exact identity of compounds. These include (i) quantification and confirmation of compound/s with LC-MS/MS using authentic standard compounds and, (ii) determining structural similarities and differences when compared to other plant-, animal- or human-derived adrenoyl-EA, with NMR. However, to support the idea of an alternative and sustainable crop to produce $\mathrm{pCB}$ products, it would be beneficial to isolate and identify the other compounds from the HPTLC to uncover the existence of a metabolite pathway capable of producing several different $\mathrm{pCB}$ or pCB-like compounds.

\section{Supplementary information}

Supplementary information accompanies this paper at https://doi. org/10.1186/s13104-020-05372-z.

Additional file 1: Figure S1. HPTLC phytochemical profile of Leonotis leonurus var. albiflora Benth. whole flower extracts, using different solvent concentrations for extraction. Phytochemical extractions were optimized using different concentrations (1,50\%; 2, 75\%; 3, 100\%, respectively) of either acetonitrile (A) or methanol (M). Mobile phase: chloroform, 10\% methanol. Loading volume: $12 \mu \mathrm{L}$. pCB-specific compounds were derivatized with fast blue B reagent (dissolved in 0.1\%, $1 \mathrm{mM} \mathrm{NaOH}$ ) under dark conditions. HPTLC plates were captured under visible light following derivatization. A single spot, based on the red-orange colour development $(A 2 ; 75 \%$ acetonitrile extraction, indicated in the red dotted-line rectangle), was isolated from the HPTLC plate and used for downstream LC-MS/MS analyses.

\section{Abbreviations}

pCB: Phytocannabinoid; HPTLC: High performance thin layer chromatography; LC-MS/MS: Liquid chromatography linked to tandem mass spectrometry; CM: Conventional medicine; TM: Traditional medicine; THC: Tetrahydrocannabinol; CBD: Cannabidiol; NMR: Nuclear Magnetic Resonance.

\section{Acknowledgements}

Not applicable.

\section{Authors' contributions}

$\mathrm{BL}$ and $\mathrm{SP}{ }^{1}$ conceived the original idea for this research project and dually serve as principal investigators. EH conducted metabolite extractions, HPTLC and LC-MS/MS analyses. MS designed the LC-MS/MS approach as part of the central analytical facility services (CAF) at Stellenbosch University. JK provided student support in the form of a scholarship. SP ${ }^{3}$ provided intellectual input as a human cancer specialist. All authors (EH, MS, JK, SC, SP' $\left.\mathrm{SP}^{3}, \mathrm{BL}\right)$ contributed equally to the writing of this research note. All authors read and approved the final manuscript.

Funding

Not applicable.

\section{Availability of data and materials}

Any data, including the full LC-MS/MS datasets, used and/or analysed during the current study are available from the corresponding author (bianke@sun. ac.za) on reasonable request.

\section{Ethics approval and consent to participate}

Not applicable.

\section{Consent for publication}

Not applicable.

\section{Competing interests}

Not applicable.

\section{Author details}

${ }^{1}$ Department of Genetics, Institute of Plant Biotechnology, Faculty of Agrisciences, Stellenbosch University, Stellenbosch, South Africa. ${ }^{2}$ Central Analytical Facilities, Stellenbosch University, Stellenbosch, South Africa.

${ }^{3}$ Department of Human Biology, Faculty of Health Sciences, University of Cape Town, Cape Town, South Africa.

Received: 23 Auqust 2020 Accepted: 31 October 2020

Published online: 10 November 2020

\section{References}

1. World Health Organization. https://www.who.int/traditional-complement ary-integrative-medicine/publications/trm_strategy14_23/en/. Accessed 5 Apr 2019.

2. Parasuraman S. Herbal drug discovery: challenges and perspectives. CurrPharmacogenomics Person Med. 2018. https://doi. org/10.2174/1875692116666180419153313.

3. Hazekamp A. The trouble with CBD oil. Med Cannabis Cannabinoids. 2018;1:65-72. https://doi.org/10.1159/000489287.

4. Bielawiec P, Harasim-Symbor E, Chabowski A. Phytocannabinoids: useful drugs for the treatment of obesity? Special focus on cannabidiol. Front Endocrinol. 2020;11:114. https://doi.org/10.3389/fendo.2020.00114.

5. Casey S, Vaughan C. Plant-based cannabinoids for the treatment of chronic neuropathic pain. Medicines. 2018;5(3):67. https://doi. org/10.3390/medicines5030067.

6. Di Marzo V, Bifulco M, De Petrocellis L. The endocannabinoid system and its therapeutic exploitation. Nat Rev Drug Discov. 2004;3:771-84. https:// doi.org/10.1038/nrd1495.

7. Dinu A, Rogobete A, Bratu T, Popovici S, Bedreag O, Papurica M, Bratu L, Sandesc D. Cannabis sativa revisited-crosstalk between microRNA expression, inflammation, oxidative stress, and endocannabinoid response system in critically ill patients with sepsis. Cells. 2020;9:307. https://doi.org/10.3390/cells9020307.

8. Maione S, Costa B, Di Marzo V. Endocannabinoids: a unique opportunity to develop multitarget analgesics. Pain. 2013;154(Suppl 1):S87-93. https:// doi.org/10.1016/j.pain.2013.03.023.

9. Hanuš L, Meyer S, Muñoz E, Taglialatela-Scafati O, Appendino G. Phytocannabinoids: a unified critical inventory. Nat Prod Rep. 2016:33:1357-92. https://doi.org/10.1039/C6NP00074F.

10. Mazimba O. Leonotis leonurus: a herbal medicine review. J Pharmacogn Phytochem. 2015;3:74-82.

11. Nsuala B, Enslin G, Viljoen A. "Wild cannabis": a review of the traditional use and phytochemistry of Leonotis leonurus. J Ethnopharmacol. 2015;174:520-39. https://doi.org/10.1016/j.jep.2015.08.013.

12. Nsuala B, Kamatou G, Sandasi M, Enslin G, Viljoen A. Variation in essential oil composition of Leonotis leonurus, an important medicinal plant in South Africa. Biochem Syst Ecol. 2017;70:155-61. https://doi. org/10.1016/j.bse.2016.11.009. 
13. Routaboul JM, Kerhoas L, Debeaujon I, Pourcel L, Caboche M, Einhorn $J$, Lepiniec L. Flavonoid diversity and biosynthesis in seed of Arabidop sis thaliana. Planta. 2006;224:96-107. https://doi.org/10.1007/s0042 5-005-0197-5

14. Loedolff B, Brooks J, Stander M, Peters S, Kossmann J. High light bio-fortification stimulates de novo synthesis of resveratrol in Diplotaxis tenuifolia (wild rocket) micro-greens. Funct Food Health Dis. 2017;7:859-72.

15. Galand N, Ernouf D, Montigny F, Dollet J, Pothier J. Separation and identification of Cannabis components by different planar chromatography techniques (TLC, AMD, OPLC). J Chromatogr Sci. 2004;42:130-4. https:// doi.org/10.1093/chromsci/42.3.130.

16 Brenneisen R. Chemistry and analysis of phytocannabinoids and other Cannabis constituents. In: ElSohly MA, editor. Marijuana and the cannabinoids. Forensic science and medicine. Totowa: Humana Press; 2007. p. $17-49$.

17. Sud M, Fahy E, Cotter D, Azam K, Vadivelu I, Burant C, Edison A, Fiehn O, Higashi R, Nair KS, Sumner S, Subramaniam S. Metabolomics Workbench: an international repository for metabolomics data and metadata, metabolite standards, protocols, tutorials and training, and analysis tools. Nucleic Acids Res. 2016;44:D463-70. https://doi.org/10.1093/nar/gkv10 42.

18. Singh R. Medicinal plants: a review. J Plant Sci. 2015;3:50-5. https://doi. org/10.11648/j.jps.s.2015030101.18.

19. Ahn K. Worldwide trend of botanical drug and strategies for developing global drugs. BMB Rep. 2017;50:111-6. https://doi.org/10.5483/bmbre p.2017.50.3.221.

20. Katchan V, David P, Shoenfeld Y. Cannabinoids and autoimmune diseases: a systematic review. Autoimmun Rev. 2016;15:513-28. https://doi org/10.1016/j.autrev.2016.02.008.
21. Movahed $P$, Jönsson B, Birnir B, Wingstrand J, Jørgensen T, Ermund A, Högestätt E. Endogenous unsaturated $C 18 \mathrm{~N}$-acylethanolamines are vanilloid receptor (TRPV1) agonists. J Biol Chem. 2005;280:38496-504. https:// doi.org/10.1074/jbc.M507429200.

22. Zendulkar O, Dovrtelova G, Noskova K, Turjap M, Sulcova A, Hanus L, Jurica J. Cannabinoid and cytochrome P450 interactions. Curr Drug Metab. 2016;17:206-26. https://doi.org/10.2174/13892002176661512101 42051.

23. Luis A, Perez T, Madalina S, Matias A, Angel R. Alkamides from Tropaeolum tuberosum inhibit inflammatory response induced by TNF-a and NF. J Ethnopharmacol. 2019;235:199-205. https://doi.org/10.1016/j. jep.2019.02.015.

24. Watson J, Kim J, Das A. Emerging class of omega-3 fatty acid endocannabinoids and their derivatives. Prostaglandins Other Lipid Mediat. 2019;143:106337. https://doi.org/10.1016/j.prostaglandins.2019.106337.

25. Cristino L, Bisogno T, Di Marzo V. Cannabinoids and the expanded endocannabinoid system in neurological disorders. Nat Rev Neurol. 2020;16:9-29. https://doi.org/10.1038/s41582-019-0284-z.

26. Massi P, Solinas M, Cinquina V, Parolaro D. Cannabidiol as potential anticancer drug. Br J Clin Pharmacol. 2013;75(2):303-12. https://doi.org/10.11 11/j.1365-2125.2012.04298.x.

\section{Publisher's Note}

Springer Nature remains neutral with regard to jurisdictional claims in published maps and institutional affiliations.
Ready to submit your research? Choose BMC and benefit from:

- fast, convenient online submission

- thorough peer review by experienced researchers in your field

- rapid publication on acceptance

- support for research data, including large and complex data types

- gold Open Access which fosters wider collaboration and increased citations

- maximum visibility for your research: over 100M website views per year

At BMC, research is always in progress.

Learn more biomedcentral.com/submissions 